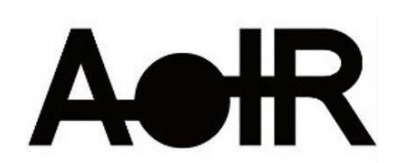

Selected Papers of \#AoIR2021:

The 22nd Annual Conference of the

Association of Internet Researchers

Virtual Event / 13-16 Oct 2021

\title{
ON(LINE) TRANSPARENCY AND THE BLACK PUBLIC SPHERE
}

\author{
Brendan Mahoney \\ Annenberg School for Communication, University of Pennsylvania
}

\section{Extended Abstract}

The Black public sphere, defined by scholars like Fraser (1990) and Squires (2002) as the space in which Black citizens deliberate about their common affairs, is in many ways experiencing unprecedented growth today in America. Just this summer, what some have called the largest protest movement in American history was staged by the Movement for Black Lives against racialized police brutality (Buchanan et al., 2020). Integral to the emergence and success of this movement from its inception in 2013 have been members of Black publics, who have succeeded in circulating discourse that draws attention to the specific issues impacting the community (Jackson \& FoucaultWelles, 2016). Alongside this movement, other publics have emerged to support not only resistance against institutions and acts of White supremacy but the creation of independent Black community, culture, and joy (Brock, 2018). Still more groups have emerged to support different segments of the Black public sphere, discussing for example issues that are specific to Black women or the Black trans community (Jackson et al., 2020). Central to the rise of all these aforementioned publics has been social media platforms. Their ability to continually mobilize mass demonstrations, sway media coverage, and more has likely been made possible by a number of digital affordances.

This proliferation of Black publics online has sparked a debate over whether the internet is ultimately a tool for liberation or racist oppression. The proponents of the internet point to the aforementioned growth online as evidence of the technology's liberatory potential. They argue that through "connective action," which allows one-to-one interactions online to mobilize a cohesive social network, millions of people can work toward the same goals without leaders, without organizations, and without trouble (Tufekci, 2017). Some scholars have in the past gone so far as to make near-utopian promises about social media's potential to revolutionize social groups, movements, and even revolutions by making communication easier than it has ever been (Bennett \& Segerberg, 2012). However, there are other scholars who warn against this technooptimism, and not without reason. In addition to protest movements and joyous satellite publics, social media platforms have become sites of brutal surveillance and racismand some believe that this is precisely the point. Critical data studies has explored the ways in which the innovations of the Information Age are rooted very deeply in existing Suggested Citation (APA): Mahoney, B. (2021, October). On(line) Transparency and the Black Public Sphere. Paper presented at AolR 2021: The 22nd Annual Conference of the Association of Internet Researchers. Virtual Event: AolR. Retrieved from http://spir.aoir.org. 
structures of inequality and the ways in which the affordances of these new technologies are carefully constructed to benefit people in power (boyd \& Crawford, 2014; van Dijck, 2013). Some have even gone so far as to suggest that internet technology may as a result only ever hurt marginalized communities online more than it helps them (Schradie, 2019; Owen, 2017).

So, who's right? Is the internet a tool of Black liberation or oppression? At the risk of disappointing my reader, this question will not be answered here. Rather, this paper attempts to move past this binary that's become stuck in the scholarly gears by synthesizing the two literatures. It will put them side by side and consider how both arguments may be correct. From this literature review, I ultimately argue that the internet's affordances were designed to uphold oppressive power structures and that it is precisely because of rather than in spite of those affordances that liberatory movements have been able to emerge. There is then no friction between the two sides of this debate, and both literatures can offer insight to the continuing success of these publics.

I will make this argument by putting the theoretical construct of the Black public in conversation with a platform affordance discussed often in critical internet studies: transparency. By "transparency," I mean the discourses and platform features that are designed to encourage as much openness, as much sharing of information as possible, with both the other site users and the site itself. Transparency seeks to make clear, to level walls, to uncover the buried or hidden. The imperative of transparency is in many ways central to the emergence of social media (not to mention much of Western society over the past several centuries), and it therefore has simultaneously played a role in the emergence of the aforementioned Black publics while also presenting a threat to them that should not be ignored. Many of transparency's goals-to clarify, to expose-are both central and antithetical to the functions of Black publics.

Over the course of this paper, I draw on a variety of different literatures to elaborate on and substantiate this argument. As the relationship between Black publics and transparency is itself certainly not a product of the internet, I begin by tracing both the threats and opportunities that transparency has presented throughout history; among these historical threats are the repression or co-optation of Black publics by the institutions of White, mainstream publics, whereas the opportunities of transparency include the chance to articulate the struggles as well as accomplishments of one's public. I then move on to outline exactly how transparency has been coded into and made manifest on social media platforms, drawing on seminal critical histories of the 
internet to tease out the influences of the state and the market. I follow with how the aforementioned threats and opportunities of transparency have migrated to cyberspace and are currently impacting the members of Black publics online. I then discuss exactly how this review represents one cohesive timeline, in which liberation and repression both precede and co-exist on the internet. Finally, I end my essay with an attempt at thinking-specifically, I give some thought as to how this more holistic view of the internet's relationship to Black publics allows us to better theorize digital strategy.

\section{References}

Bennett, W. L., \& Segerberg, A. (2012). The Logic of Connective Action: Digital media and the personalization of contentious politics. Information, Communication \& Society, 15(5), 739-768. https://doi.org/10.1080/1369118X.2012.670661

boyd, danah, \& Crawford, K. (2012). Critical Questions for Big Data: Provocations for a cultural, technological, and scholarly phenomenon. Information, Communication \& Society, 15(5), 662-679. https://doi.org/10.1080/1369118X.2012.678878

Brock, A. (2018). Distributed Blackness: African American Cybercultures. NYU Press.

Buchanan, L., Bui, Q., \& Patel, J. K. (2020, July 3). Black Lives Matter May Be the Largest Movement in U.S. History. New York Times.

https://www.nytimes.com/interactive/2020/07/03/us/george-floyd-protests-crowdsize.html

Fraser, N. (1990). Rethinking the Public Sphere: A Contribution to the Critique of Actually Existing Democracy. Social Text, 25/26, 56-80.

Jackson, S. J., Bailey, M., \& Foucault Welles, B. (2020). \#HashtagActivism: Networks of Race and Gender Justice. MIT Press.

Jackson, S. J., \& Foucault Welles, B. (2016). \#Ferguson is everywhere: Initiators in emerging counterpublic networks. Information, Communication \& Society, 19(3), 397418. https://doi.org/10.1080/1369118X.2015.1106571

Owen, S. (2017). Monitoring social media and protest movements: Ensuring political order through surveillance and surveillance discourse. Social Identities, 23(6), 688-700. https://doi.org/10.1080/13504630.2017.1291092 
Schradie, J. (2019). The Revolution that Wasn't. Harvard University Press.

Squires, C. R. (2002). Rethinking the Black Public Sphere: An Alternative Vocabulary for Multiple Public Spheres. Communication Theory, 12(4), 446-468.

Tufekci, Z. (2017). Twitter and Tear Gas: The Power and Fragility of Networked Protest. Yale University Press.

van Dijck, J. (2013). The Culture of Connectivity: A Critical History of Social Media. Oxford University Press. 